\title{
ATUAÇÃO DO PSICÓLOGO ESCOLAR NA REDE PÚBLICA DE ENSINO, DA TEORIA À PRÁTICA: uma revisão bibliográfica conceitual
}

DOI: $10.22289 / 2446-922 X . V 3 N 2 A 6$

:André Luiz Ferreira Evangelista ${ }^{1}$

Alessander Freitas do Amaral

\section{RESUMO}

As perspectivas relacionadas ao trabalho do psicólogo na escola pública tendem a se fundamentar apenas em atendimentos clínicos, com enfoques limitados e ações descontextualizadas. O objetivo deste estudo, por conseguinte, é reconhecer as contribuições, os desafios e as oportunidades pertinentes à prática psicológica, especialmente no que se refere à função específica do psicólogo escolar e seu comprometimento com a formação do aluno na escola pública. O trabalho foi realizado por meio de uma revisão bibliográfica conceitual, fundamentada em produções científicas disponíveis em base de dados indexadas. Como resultado, observou-se que a psicologia tem um papel importante no contexto escolar, mas, ainda há uma série de fatores que dificultam essa atuação, como por exemplo, a capacitação dos profissionais, pois nas universidades, os acadêmicos de psicologia nem sempre são devidamente preparados para trabalhar no processo educacional. $\mathrm{Na}$ escola, a atuação do psicólogo vai além da atuação clinica direcionada para o aluno com problemas de aprendizagem. O seu trabalho deve considerar todo o contexto social em que o aluno se encontra inserido, a cultura peculiar a escola e o perfil dos profissionais que dela fazem parte. Há de se observar que o processo de desenvolvimento infantil e de aprendizagem é bastante complexo e sofre influência direta de inúmeros fatores. Torna-se importante que essa área de conhecimento seja estimulada com mais publicações relacionadas. E que as instituições de ensino superior se atentem para a necessidade de capacitar os graduandos para atuarem junto as instituições escolares, de forma a compreender os objetivos e as exigências dessa função para este contexto.

Palavras-chave: Educação; Psicologia Escolar; Ensino público.

\footnotetext{
${ }^{1}$ Endereço eletrônico de contato: andrelzevangelista@terra.com.br
}

Recebido em 22/08/2017. Aprovado pelo Conselho Editorial e aceito para publicação em 10/10/2017.

Rev. Psicol Saúde e Debate. Dez., 2017:3(2):62-73. 


\section{ABSTRACT}

The perspectives related to the psychologist's work in the public school tend to be based only on clinical care, with limited focus and decontextualized actions. The aim of this study is therefore to recognize the contributions, challenges and opportunities pertinent to psychological practice, especially with regard to the specific role of the school psychologist and his commitment to student training in the public school. The work was carried out through a conceptual bibliographical review, based on scientific productions available in indexed databases. As a result, it has been observed that psychology has an important role in the school context, but, there are still a number of factors that make this performance difficult, such as the qualification of professionals, because in universities, psychology scholars are not always prepared to work in the educational process. At school, the psychologist's performance goes beyond the clinical practice directed to the student with learning problems. His work should consider all the social context in which the student is inserted, the culture peculiar to the school and the profile of the professionals who are part of it. It should be noted that the process of child development and learning is quite complex and is directly influenced by many factors. It is important that this area of knowledge be stimulated with more related publications. And that higher education institutions should consider the need to train undergraduates to work with school institutions in order to understand the objectives and requirements of this function in this context.

Keywords: Education. School Psychology. Public education.

\section{INTRODUÇÃO}

A Psicologia Escolar e Educacional é um campo de atuação muito importante. Os psicólogos que trabalham junto às escolas se dedicam ao ensino e à pesquisa referente à Psicologia e a Educação, essa área de conhecimento objetiva compreender as dimensões subjetivas do ser humano. São inúmeras as concepções teórico-metodológicas que o auxiliam na prática escolar. Essa disciplina envolve além dos processos de ensino e aprendizagem, questões do desenvolvimento humano, como escolarização, inclusão de portadores de deficiências, políticas públicas, gestão psicoeducacional, avaliação psicológica e formação continuada de professores (Abrapee, 2017).

Há necessidade de se fazer uma apreciação crítica da atuação do psicólogo escolar na rede pública de ensino, para distinguir uma linha de ação adequada, de maneira que esse profissional possa atuar com competência na escola e, de fato, trazer contribuições para esse meio. Há necessidade de se propor debates sobre a relação entre a educação e a psicologia, visando refletir sobre contribuições, desafios e oportunidades intrínsecas à atuação do psicólogo no ambiente escolar. Sabe-se que o psicólogo tem muito a oferecer à conjuntura escolar, mas ainda se observa uma desarticulação entre as propostas previstas teoricamente e a perspectiva de estas serem aplicadas na prática.

Rev. Psicol Saúde e Debate. Dez., 2017:3(2):62-73. 
A educação expressa a competência de um povo se aparelhar e construir o seu futuro, logo, não ocorre por acaso, todavia, como efeito de um esforço significativo. Enquanto que a psicologia escolar objetiva promover o desenvolvimento humano, no entanto, ainda não é largamente difundida. O êxito do psicólogo escolar requer que os seus propósitos sejam claros, já que o mesmo enfrenta um duplo desafio. O primeiro é ser aceito na escola, sem ter sua função restrita a promover o desenvolvimento do aluno e o segundo desafio é receber apoio da instituição para propor atividades preventivas que contribuam para o crescimento do aluno, baseadas nos processos cognitivo, afetivo, social, físico e no progresso da sua interação social (Valle, 2003).

As perspectivas da escola pública em relação ao psicólogo, ainda estão, em boa parte, fundamentadas nos atendimentos clínicos, com enfoques limitados e ações descontextualizadas. Em contradição com esse tipo de representação, emergem as demandas de se trabalhar a escola como um grande sistema, o que leva o profissional a atuar junto a diferentes atores, como corpo docente, alunos e famílias, tendo que prestar uma atenção desarticulada. Assim, conteúdos, estratégias e projetos idealizados para a psicologia escolar deixam de subsidiar escola/professor/aluno, relação esta, importante para consolidar a proposta da educação que é preparar cidadãos críticos e competentes, cujos valores sejam pautados na moral e na ética (Miranda, 2007).

O objetivo do estudo foi de reconhecer as contribuições, desafios e as oportunidades associadas à prática psicológica, principalmente no que se refere à função específica do psicólogo escolar em seu comprometimento com a formação do aluno na escola pública.

Para confeccionar o artigo, primeiramente, foram analisados os títulos dos artigos com a intenção de descartar referências repetidas. Em seguida, selecionaram-se os resumos anexados e foi realizada uma leitura prévia para escolher a seleção do material necessário para o estudo. Foram adotados os seguintes critérios de inclusão: (1) palavras descritoras presentes no corpo do texto, (2) idioma: artigos que foram publicados na integra em Português, 3) formato: selecionaram referências publicadas como artigo, relato de experiência ou revisão da literatura científica e foram abdicadas as referências publicadas como resenha, carta ao editor e resumo, 4) foram selecionadas apenas as referências relacionadas ao tema. Trata-se de um estudo do tipo qualitativo descritivo de revisão bibliográfica conceitual. Para a revisão do conceito pautou-se na temática atuação do psicólogo escolar na rede pública.

$\mathrm{Na}$ medida em que foi sendo selecionado o material teórico, chamou a atenção o fato de os artigos especificamente sobre a condição da atuação do psicólogo nas escolas, ser a mesma, independentemente de ter sido publicado há cerca de 29 anos, fato que revela que o tratamento dado a psicologia escolar permanece praticamente inalterado, e mesmo que 
brevemente, constata-se esta afirmativa na primeira seção deste estudo, 'Psicologia Escolar', ou seja, ao menos nos artigos consultados publicados de 1984 a 2013, não se observa nenhuma conquista robusta no papel da psicologia na educação escolar. Não se teve a intenção de se fazer uma extenuante análise histórica do tema, mas considerou-se ser este um ponto importante a ser destacado neste estudo, de forma a enfatizar que esta área não vem recebendo o tratamento que lhe é devido.

\section{PSICOLOGIA ESCOLAR: um breve retrospecto}

Em 1984, Andaló já relatava que o profissional de psicologia ainda não havia conquistado o seu espaço de atuação e sua identidade no contexto escolar, sendo a formação acadêmica uma das principais causas dessa realidade. Esta autora já dizia, que para atuar nesta área, o profissional deveria se apoiar em teorias que enfatizassem fatores objetivos e subjetivos do processo de aprendizagem, de modo a considerar as condições socioculturais e a relação professor/aluno. O foco não deveria ser apenas o indivíduo com problemas de aprendizagem, mas em todos os sujeitos envolvidos nessa relação. A autora ainda relata ser a Psicologia Escolar uma área secundária da Psicologia, erroneamente tida como simples, que não necessita de muito preparo ou experiência, sendo pouco valorizada. Embora ainda mal delimitada, está área era vista como extremamente complexa, por envolver a cultura institucional, o processo de ensino e aprendizagem, a relação professor-aluno e as transformações sociais. Ressalta-se não se tratar de voltar todas as atenções ao aluno e as suas dificuldades, a atuação do psicólogo no ambiente escolar requer uma análise global que avalie a realidade escolar conjuntamente (Andaló, 1984)

Em 1995, Almeida observou que o psicólogo, genericamente dispunha de poucas oportunidades para obter conhecimentos teórico-metodológicos em ciências humanas e sociais não ligadas ao eixo saúde-doença, uma vez que a sua formação ocorria principalmente clínica e a psicologia é tida como "Ciência da Saúde". Ao exigir do psicólogo escolar, uma atuação baseada em teorias e práticas educacionais, exige-se além daquilo que lhe foi ensinado na universidade. Eram necessárias mudanças em seus padrões de atuação, nos modelos dominantes, para deter todo o conhecimento psicológico adequado à escola. Esta autora, advertiu que o psicólogo da educação, não é nem um psicólogo clínico, nem um psicólogo escolar, logo, nem sempre a atuação gera bons resultados, pois, o profissional não está preparado para atuar no processo ensino-aprendizagem, e a sua atuação pode variar entre práticas clínicas e psicopedagógicos (Almeida, 1995).

Rev. Psicol Saúde e Debate. Dez., 2017:3(2):62-73. 
Em 2001, Cabral enfatizou haver uma necessidade de se repensar o papel do psicólogo escolar, pois a sua atuação deveria ir além do acompanhamento individual do aluno e abranger uma análise de intervenções a serem feitas nas instituições educacionais a fim de integrar a criança com a instituição de ensino. Para tanto, o profissional deveria entender a importância dessa atuação e buscar caminhos alternativos para preparação, através dos cursos de graduação e pós-graduação que de fato o preparem para conseguir ter visão crítica dos diferentes aspectos da realidade social e política dentro contexto escolar (Cabral, 2001)

A área de Psicologia Escolar prossegue esbarrando em deficiências, principalmente no que tange as formulações teóricas que são suporte metodológico à prática profissional. Uma das principais razões apontadas para esta deficiência é a formação acadêmica, pois argumenta-se que ela não oferece, de forma satisfatória, práticas psicológicas no contexto escolar. Razão pela qual os autores apontam para a necessidade de uma produção teórica mais consistente e sistematizada, que possibilite aos profissionais uma ressignificação no que tange às práticas escolares, com foco não só no indivíduo, mas em todos os sujeitos e fatores envolvidos na relação de ensino e aprendizagem (Neves, 2002).

A atuação do psicólogo nas escolas despertava para requerer o reconhecimento deste profissional que, em 2003, ainda ficava a desejar na esfera da educação, e como consequência foram surgindo desafios para os psicólogos, sendo um deles a inclusão na escola, a fim de que seu trabalho não fosse distorcido ou limitado no campo competitivo que envolve a afirmação de papéis de poder, pois a intenção é que a Psicologia e Pedagogia se complementem para alcançar os objetivos idealizados. Outro desafio consiste na proposta de uma atuação preventiva, que envolva a escola e a família, e não apenas uma atuação voltada para a clínica. Já se questionava que, o Brasil, para ser considerado um país desenvolvido, deveria ser necessário que a atenção dada à educação fosse revista, pois esta necessitava de investimentos para superar as suas deficiências. Nesse contexto, o desenvolvimento psicossocial torna-se indispensável para elaboração de estratégias hábeis a mudar a realidade educacional, ponto em que a atuação do psicólogo se reveste de extrema importância (Valle, 2003).

Observa-se que o debate sobre o trabalho do psicólogo escolar foi ganhando formas mais especificas, pois, em 2005, Vokoy \& Pedrosa lembram que o psicólogo junto à criança, deve se ater para as relações sociais nas quais ela está inserida, sem desconsiderar que também existem crianças que necessitam de atendimento individual, sempre levando em conta os conflitos inerentes ao desenvolvimento infantil. Dentre as ações sugeridas para o psicólogo dentro das instituições escolares tem-se: contribuir para uma gestão escolar democrática adotando um trabalho coletivo e solidário; ampliar a participação da comunidade 
na escola; e orientar na escolha de materiais didáticos que contribuam para o pensamento crítico e criativo dos alunos (Vokoy \& Pedroza, 2005).

O trabalho do psicólogo escolar passa a ser visto como intimamente ligado a questão do fracasso escolar, um grave problema social, encontrado principalmente nas classes mais baixas. Para uma atuação capaz de enfrentar efetivamente essa questão, o psicólogo deve considerar o professor como coparticipante do trabalho com aluno e agregar as modalidades de atendimento psicopedagógico às modalidades de atuação de promoção à saúde. Seu trabalho deve enfatizar o processo de construção e apropriação do conhecimento, sem desconsiderar as interações da relação professor-aluno, bem como as condições sociais, políticas e educacionais, vez que estes fatores estão intimamente relacionados com as dificuldades apresentadas pelos alunos (Neves, 2006).

Mas recentemente, constata-se, porém, que a inserção do psicólogo na escola não é reconhecida pelas Diretrizes e Bases da Educação Nacional (LDB) como ação da educação, mas, a sua atuação pode tem caráter educacional, vez que é pautada na escola e em suas demandas. A atuação do psicólogo deve ser discutida para constante melhoria da educação e pela questão de natureza ética dessa área, pois as discussões da LDB devem questionar sobre o que deve ser feito, para quem, com que finalidade e com qual interesse. Logo, a Psicologia Escolar deve ser comprometida com uma educação de fato democrática, que atenda o interesse de todas as classes (Antunes, 2008).

A formação do Psicólogo no Brasil é voltada principalmente para perspectiva clínica e de saúde mental, no entanto, os profissionais de psicologia são capazes de contribuir significativamente para melhorar os processos educacionais. Pois cabe ao psicólogo e não ao professor realizar diagnósticos e intervenções preventivas ou corretivas em grupos ou de forma individual, considerando questões acerca do desenvolvimento humano, relações interpessoais, mecanismos e processos de aprendizagem (Oliveira, 2009).

A Psicologia Escolar necessita ampliar a sua atuação para promover o desenvolvimento e a aprendizagem do aluno e dar assistência a sua família. O papel do psicólogo junto aos professores é importante para que sejam desenvolvidas ações que possibilitem aos professores sentirem-se participantes ativos nos processos de sucesso escolar. O psicólogo deve ainda acompanhar a saúde psíquica dos docentes, pois não é raro se deparar com professores cansados, abatidos e desmotivados, o que implica diretamente no aprendizado dos alunos (Oliveira, 2009).

A atuação do psicólogo nas escolas passou por momentos de 'crise' e seu espaço vinha sendo ocupado pela Psicopedagogia, que possui foco na criança com dificuldades escolares. O desafio principal da Psicologia Escolar é o de superação desse momento, 
devendo ampliar a dimensão educativa e se fazer presente em diversos campos educacionais, tais como: atuando com projetos de inclusão social, planejamento de ações comunitárias e sociais, de ação junto a jovens em liberdade assistida; prevenção de doenças sexualmente transmissíveis (Souza, 2009).

Os psicólogos escolares e educacionais trabalham em múltiplos espaços educativos como: casas abrigos, programas de educação comunitária, penitenciárias, entre outros. A importância do trabalho dos psicólogos escolares se dá pelo fato de a utilização da Psicologia no contexto escolar contribuir para aperfeiçoar o complexo processo educativo. A atuação dos psicólogos desde a educação infantil até a educação à distância, contribui para um aprendizado sólido e eficaz, porém, para tanto, é necessária uma revisão e o aprimoramento das práticas profissionais nesse contexto (Martinez, 2009).

A atuação do psicólogo escolar deve contribuir para uma formação mais ampla, técnica, interdisciplinar e crítica dos estudantes dentro da realidade da escola. Esse profissional deve trabalhar sem reduzir os jovens à condição de alunos e considerar toda a complexidade dos vários fenômenos próprios da instituição de ensino (Dazzani, 2010).

É comum os psicólogos se formarem sem terem tido qualquer contato com a atuação na área da educação, o que faz com que a sua atuação fique focada no indivíduo. Raramente um psicólogo vai à escola investigar as condições em que ocorrem as dificuldades de aprendizagem (Asbahr, 2011).

A maioria das discussões sobre a Psicologia escolar é no que tange ao problema da formação, pois a graduação não costuma prepara-los para atuação nas escolas. Os cursos de graduação e pós-graduação devem se ater para os novos modelos de atuação mais compatíveis com o contexto da educação, formando psicólogos capazes de atuar com políticas e instituições públicas, preparados para lidar com situações do dia a dia das escolas e intervir na comunidade educacional (Dazzani, 2010).

O psicólogo deve analisar também a instituição, examinando a eficiência e a qualidade do processo educacional, trabalhando com toda equipe escolar para que tenham uma formação teórica que englobe tanto às teorias da psicologia, quanto a literatura educacional. Logo, faz-se necessária a inserção do estudante de psicologia nas escolas, de modo que sua formação o prepare para cotidiano escolar e as situações inerentes a esse contexto (Asbahr, 2011).

Também, o psicólogo não pode deixar de se ater aos encaminhamentos escolares, compreendendo o processo de escolarização e sem considerar a queixa escolar como mero reflexo de problemas emocionais, mas sim como fruto das relações escolares. É importante ainda, que haja uma formação profissional adequada para que propicie o atendimento das 
queixas escolares e articulação de ações entre os psicólogos que atuam na área da educação (Vebber, 2013).

Face ao exposto, mesmo com todos desafios enfrentados pela psicologia escolar, nos últimos anos, pode-se constatar que é possível a prática psicológica para a formação do aluno na escola pública, assim como se observa nos relatos demonstrados na seção seguinte.

\section{PRÁticA PSICOLÓGICA PARA A FORMAÇÃO DO ALUNO NA ESCOLA PÚBLICA}

Estudo apresenta relato de experiência sobre um projeto realizado em uma escola pública do Rio Grande do Sul, que tem cerca de 600 alunos. As intervenções do psicólogo são realizadas em conjunto com professores e direção e as principais atividades do psicólogo são: entrevistas e anamnese no ingresso escolar; reunião de pais e palestras sobre desenvolvimento infantil e aprendizagem, limites, sexualidade, transtornos de aprendizagem e desenvolvimento; entrevistas de acompanhamento com a família; reuniões pedagógicas e com conselhos de classe, assessoria aos professores; acompanhamento do aluno junto aos professores e a família para superação de dificuldades, reuniões com profissionais especialistas de outras áreas e oficinas pedagógicas com os alunos. O planejamento de atividades com alunos é realizado nas reuniões pedagógicas com os professores, nestas o psicólogo escuta as demandas da escola, analisa a realidade apresentada e traça estratégias de intervenção, de modo a orientar e a planejar atividades. O Plano de ensino é delineado de acordo com a necessidade da turma e considera a boa convivência e a construção da identidade. Os resultados mostram que na percepção dos alunos houve aprimoramento nas relações e redução de brigas. O psicólogo escolar pode contribuir para dinamizar as atividades escolares e melhorar a relação entre todas as partes, o que favorece a construção de uma sociedade fortalecida por valores humanos (Vebber, 2013).

Estudo apresenta relato de experiência de estágio obrigatório em Psicologia escolar desenvolvido em uma instituição pública de Educação Infantil, abordando a importância de haver uma relação entre educadoras e pais. O objetivo do trabalho foi apresentar uma intervenção que promovesse uma aproximação entre a escola e os pais. Para tanto, valeramse de estratégias, como murais informativos e encontros de orientações para os pais. É importante se ter em mente, que para uma assistência global da criança, a de se considerar todas as suas relações do âmbito educacional, bem como entre pais e escola, razão pela qual

Rev. Psicol Saúde e Debate. Dez., 2017:3(2):62-73. 
acredita-se que a atuação do psicólogo escolar deve ser voltada também para promover o contato entre a família e a escola (Delvan, 2002).

Ainda sobre experiências reais da atuação do psicólogo no ambiente escolar. Foi realizado um trabalho em uma escola de ensino fundamental que buscou oferecer educação sexual para adolescentes. A intervenção foi realizada por meio de 15 encontros semanais, valendo-se de diversas estratégias metodológicas que abordavam os temas como: regras de convívio grupal; conceito de sexualidade; saúde sexual e reprodutiva; iniciação sexual; gravidez na adolescência, violência sexual; e gênero e diversidade sexual. Na realização do projeto, buscou-se citar os conceitos trazidos pelos alunos e complementa-los através da incorporação de conhecimentos científicos sobre os temas, a fim de contribuir para o processo de humanização dos alunos (Maia, 2012).

Um relato sobre a experiência obtida durante o estágio supervisionado de Psicologia Escolar, foi desenvolvido em uma escola de Ensino Fundamental Municipal e outra de Educação Infantil Privada, no interior de São Paulo, com o objetivo de proporcionar a experiência da vivência do psicólogo no ambiente escolar. O estudo foi desenvolvido em duas etapas, no primeiro semestre, por meio da técnica de observação participante, foi realizada uma caracterização institucional e definidas as estratégias de intervenção. A segunda foi à intervenção, onde juntamente aos professores, trabalharam-se com os alunos a psicomotricidade, coordenação motora fina e equilíbrio corporal. Nesta etapa, foi realizada ainda, uma espécie de plantão psicológico para pais, educadores e alunos. Constatou-se, que a escola e os professores estão menos resistentes a atuação do profissional da psicologia nas escolas (Matos, 2014).

Estudo analisou a importância da atuação do psicólogo na solução dos problemas de aprendizagem com origem em distúrbios psicológicos e identificou práticas que funcionem neste sentido aponta três vertentes: (1) o motivo do fracasso escolar não se devem somente à escola e na relação professor/aluno. Por vezes, o êxito na aprendizagem sujeita a dissolução de problemas psicológicos, fato que solicita a intervenção de um profissional da psicologia; (2) a atuação do psicólogo na instituição escolar não pode se restringir a atender o educando e a sua família, orientar o profissional da educação, ou seja, professor, orientador, supervisor é essencial para ocorrer a superação dos barreiras psicológicas da aprendizagem; (3) o psicólogo escolar deve atuar não somente de forma curativa, mas especialmente com enfoque na prevenção (Moreira \& Oliveira, 2016).

Importante lembrar-se ainda de que, vem sendo cada vez mais percebida a participação de adolescentes em atos de violência e criminalidade, atos estes que de alguma forma acabam por se desembocar no contexto escolar. Fundamentado nas vivências do 
cotidiano escolar, o profissional da psicologia pode atuar na construção de medidas socioeducativas, de forma a desenvolver práticas que contribuam para a produção de políticas públicas norteadas a unir Estado, família e sociedade, cujo objetivo é analisar e diagnosticar junto aos profissionais que lidam com a área de medidas socioeducativas, a responsabilidade e convenções éticos com a presente e com as futuras gerações (Soares \& Mendes, 2017).

Dentro da escola, são inúmeras as possibilidades de atuação do psicólogo e dentre as atividades que por ele podem ser desempenhadas, citam-se:

programação e avaliação de ensino, estrutura curricular, projetos educacionais, estratégias de aprendizagem, avaliação visando à construção de um projeto pedagógico que possa ser assumido pelos agentes educacionais de cada escola e favoreça a interface desta com a família e a comunidade, formação continuada de professores, orientação educacional e profissional, elaboração de programas especiais voltados para dificuldades de aprendizagem e a inclusão de alunos com necessidades especiais ao ensino regular (Joly, 2000).

No entanto, para essa atuação, é fundamental que haja uma capacitação ética e flexível desse profissional para que ele esteja apto a desempenhar adequadamente suas funções. Sugere-se então, que a produção científica da área seja estimulada para contribuir para a formação continuada dos psicólogos escolares (Joly, 2000).

\section{CONSIDERAÇÕES}

O ramo da psicologia estuda o comportamento humano e seus processos mentais, razão pela qual, por sua natureza, trata-se de uma área extremamente vasta, que pode ser aplicada em diversos segmentos sociais. Dentro destes segmentos, temos a atuação do psicólogo dentro do contexto escolar, e embora a participação do profissional de psicologia, neste contexto, seja de extrema importância para a melhoria de todo o processo de ensino e aprendizagem, constatou-se que assim como em anos atrás, ainda prossegue havendo uma série de fatores que dificultam essa atuação.

No contexto escolar, a atuação do psicólogo vai além da atuação clinica direcionada especificamente para o aluno com problemas de aprendizagem, pois o trabalho do psicólogo escolar deve considerar todo o contexto social no qual o aluno está inserido, bem como deve analisar as particularidades da escola e dos demais profissionais que dela fazem parte. Pois há de se ponderar que o processo de Rev. Psicol Saúde e Debate. Dez., 2017:3(2):62-73. 
desenvolvimento infantil e de aprendizagem é bastante complexo e sofre influência direta de inúmeros fatores.

Considerando a complexidade dessa atuação, dentre os principais problemas apontados para a inserção do psicólogo no ambiente escolar, esbarramos com a capacitação desse profissional, pois embora se trate se um segmento importante de atuação, constatou-se que nas universidades, os acadêmicos de psicologia não são devidamente preparados para trabalhar no processo de educação. Desse modo, é importante que essa área do conhecimento seja estimulada com mais publicações a respeito do tema e que as instituições de ensino superior se atentem para a necessidade de capacitar os alunos para atuarem junto as escolas, compreendendo as particularidades desse trabalho.

\section{REFERÊNCIAS}

Almeida, SF. (1995). Concepções e práticas de Psicólogos Escolares acerca das Dificuldades de Aprendizagem. Psic: Teor. \& Pesq,11(2),117-134.

Antunes, MAM. (2008). Psicologia Escolar e Educacional: história, compromissos e perspectivas. Campinas; Psicol. Esc. Educ., 12(2),469-475.

Andaló, CSA. (1984). O papel do psicólogo escolar. Psicol. cienc. prof. 4 (1).

Asbahr, FSF; Martins \& Mazzolini, BPM. (2011) Psicologia, formação de psicólogos e a escola: desafios contemporâneos. Psicol. estud., 16(1).

Associação Brasileira de Psicologia Escolar e Educacional - ABRAPEE. (2017). O Psicólogo Escolar. 20(1),1.

Cabral, E; Sawaya, SM. (2001). Concepções e atuação profissional diante das queixas escolares: os psicólogos nos serviços públicos de saúde. Estudos de Psicologia, 6(2), 143155.

Dazzani, MVM. (2010). A psicologia escolar e a educação inclusiva: Uma leitura crítica. Psicol. cienc. prof. 30(2).

Delvan, JS; Ramos, MC \& Dias, MB. (2002). A psicologia escolar/educacional na educação infantil: o relato de uma experiência com pais e educadoras. Psicol. teor. prat., 4(1).

Joly, MCRA. (2000). A formação do psicólogo escolar e a educação no terceiro milênio. Psicol. esc. educ., 4(2). 
Maia, ACB; Edit, NM; Terra, BM \& Maia, GL. (2012). Educação sexual na escola a partir da psicologia histórico-cultural. Psicol. em Estudo, 17(1),151-156.

Matos, CS; Solon, MS \& Molinari, PA. (2014). Relato de experiência: A psicologia na escola. Anais da Semana de Pedagogia. Centro Universitário Barão de Mauá. 2014.

Martinez, AM. (2009). Psicologia Escolar e Educacional: compromissos com a educação brasileira. Psicol. esc. educ., 13(1).

Moreira, IG.; Oliveira, RS. (2016). A importância do trabalho do psicólogo no ambiente escolar: perspectivas da educação na atualidade. Psicologia e Saúde em debate, 2(1):14-27.

Miranda, LL. (2007). Perspectivas de atuação do psicólogo escolar na rede pública de ensino: um estudo exploratório em uma escola de Fortaleza. Psicol. educ., (25),113-129.

Neves, MBJ; Araújo, CMM. (2006). A questão das dificuldades de aprendizagem e o atendimento psicológico às queixas escolares. Aletheia, 24(1).

Neves, MBJ (2002). Formação e atuação em psicologia escolar: análise das modalidades de comunicações nos congressos nacionais de psicologia escolar e educacional. Psicol. cienc. prof., 22(2).

Oliveira, CBE; Marinho-Araujo, CM. (2009). Psicologia escolar: cenários atuais. Estud. pesqui. psicol., 9(3),648-663.

Soares, GR; Mendes, DF. (2017). A atuação do psicólogo com adolescentes infratores em medida socioeducativas. Psicologia e Saúde em debate, 2(1),117-137.

Souza, MPR. (2009). Psicologia Escolar e Educacional em busca de novas perspectivas. Revista Semestral da Associação Brasileira de Psicologia Escolar e Educacional, 13(1),179182.

Valle, LELR. (2003). Psicologia escolar: um duplo desafio. Psicol. cienc. prof., 23-(1),-22-29.

Vebber, FC. (2013). Psicologia escolar: relato de uma experiência no ensino fundamental. Psicol. teor. prat., 15(1).

Vokoy, T, Pedroza, RLS. (2005). Psicologia Escolar em educação infantil: reflexões de uma atuação. Psicol. esc. educ., 9(1). 